\title{
A method of seismic performance evaluation based seismic fragility analysis
}

\author{
Feng Wang ${ }^{1, a}$, Zhongzheng Guo ${ }^{1}$ \\ ${ }^{1}$ College of Civil Engineering, Dalian Minzu University, 116650 Dalian, China
}

\begin{abstract}
For evaluating seismic performance of structures, a method is presented based on increment dynamic analysis and seismic fragility analysis. Firstly, the failure probability equation is deduced, in which the relationships of seismic intensities and response demands can be determined by the increment dynamic analysis. On this basis the probabilities with different damage levels under different seismic intensities are obtained. Secondly, damage parameter $\mathrm{R}$ is defined and used to reflect seismic damage level of structures, damage index Re is defined and used to compare with $\mathrm{R}$ range and determine the situation of seismic damage. Finally, the procedure is proposed for evaluating structural seismic performance. In order to verify and demonstrate the method, three structural models are designed, and typical earthquake records are selected. The results of example analysis show that this method is convenient for evaluating multi-levels seismic performance of structures.
\end{abstract}

\section{Introduction}

Seismic fragility analysis is the core research module of PBEE a new-generation methodology based on total probability theory[1]. It refers to the probability of structural failure or of reaching a certain performance level under the action of ground motions of different intensities. It is a description of probability distribution of each performance state of a building structure caused by a given disaster, and is characterized by a seismic fragility curve or a seismic fragility matrix.

At present, the studies on seismic fragility analysis and its application in structural seismic evaluation have achieved a certain number of results[2-7], but at least a problem still exists that limits their application in engineering. Seismic fragility analysis results are probability and multi-level. Expressing the result as a probability is not easily accepted by engineers, as engineers prefer to use a single value to evaluate the structural damage rather than the failure probability of using multiple failure states, which hinders its application in engineering.

For this reason, a seismic performance evaluation method is proposed in this paper based on increment dynamic analysis (IDA) and seismic fragility analysis, in which a concept of damage index is presented, and is adopted to evaluate the seismic performance of structures.

\section{Seismic fragility analysis and seismic performance evaluation}

Under the action of a certain intensity ground motion, the conditional failure probability of the maximum story drift ratio $\theta_{\mathrm{m}}$ of a structure reaching or exceeding the story drift ratio limit $[\theta]$ under a certain extreme state is expressed as Pf. When both $\theta \mathrm{m}$ and $[\theta]$ obey the logarithmic normal distribution, the failure probability $\mathrm{P}_{\mathrm{f}}$ can be calculated by the following equation:

$$
P_{f}=\phi\left(\frac{\ln \mu_{\theta_{\mathrm{m}}}-\ln \mu_{[\theta]}}{\sqrt{\sigma_{\theta_{\mathrm{m}}}^{2}+\sigma_{[\theta]}^{2}}}\right)
$$

where $\mu_{[\theta]}$ and $\sigma_{[\theta]}$ are the mean and logarithmic standard deviations of the maximum story drift ratio limit of the structure, respectively, and $\mu_{\theta_{\mathrm{m}}}$ and $\sigma_{\theta_{\mathrm{m}}}$ are the mean and logarithmic standard deviation of the maximum story drift ratio of the structure under different ground motions, respectively.

The $\theta_{m}$ of the $\theta_{m}$-PGA capability curve drawn by the IDA method is averaged, and natural logarithms of the vertical and horizontal coordinates are taken to draw a capability curve $\ln \left(\mu_{\theta_{\mathrm{m}}}\right)-\ln (\mathrm{PGA})$. It can be seen from previous studies that such curves are basically in line with the linear relationship, so the regression equation is:

$$
\ln \left(\mu_{\theta_{\mathrm{m}}}\right)=a+b \ln (\mathrm{PGA})
$$

where $a$ and $b$ are regression coefficients. Substituting Eq. (2) into Eq. (1) gives:

$$
P_{f}=\phi\left\{\frac{\ln \left[e^{a}(\mathrm{PGA})^{b} / \mu_{[\theta]}\right]}{\sqrt{\sigma_{\theta_{\mathrm{m}}}^{2}+\sigma_{[\theta]}^{2}}}\right\}
$$

\footnotetext{
${ }^{a}$ Corresponding author:win_0803@163.com
} 
In this paper, Eq. (3) is used to calculate the failure probability of structures corresponding to different seismic damage grades.

The steps of seismic fragility analysis and seismic performance evaluation based on the simplified IDA method are as follows.

(1) Draw $\mu_{\theta \mathrm{m}}$-PGA capability curves of the structure by using the simplified IDA method and calculate $\sigma_{\theta \mathrm{m}}^{2}$.

(2) Take the natural logarithm of the vertical and horizontal coordinates of the $\mu_{\theta \mathrm{m}}$-PGA capability curve, and substitute it into Eq. (2) to calculate the regression coefficients $a$ and $b$.

(3) According to different damage levels, substitute PGA, $a, b, \mu_{[\theta]}, \sigma_{\theta \mathrm{m}}^{2}$, and $\sigma_{[\theta]}^{2}$ into Eq. (3) to calculate the failure probability $P_{f}$ corresponding to different seismic damage levels. Among these, $\mu_{[\theta]}$ can be determined by the upper limit of $\theta_{\max }$ corresponding to each damage level in Table $1 ; \sigma^{2}{ }_{[\theta]}$ is set to 0.399 .

Table 1. Corresponding of seismic performance levels, damage levels and maximum story drift ratios.

\begin{tabular}{|c|c|c|c|c|c|c|c|}
\hline \multirow{3}{*}{$\begin{array}{c}\begin{array}{c}\text { Performance } \\
\text { levels }\end{array} \\
\begin{array}{c}\text { Damage } \\
\text { levels }(i)\end{array}\end{array}$} & \multirow{3}{*}{$\begin{array}{l}\text { 1-th level } \\
R=0 \sim 0.2 \\
\begin{array}{c}\text { Basically } \\
\text { perfect (1) }\end{array}\end{array}$} & \multirow{2}{*}{\multicolumn{4}{|c|}{$\begin{array}{l}\text { 2-th level } \\
R=0.2 \sim 0.7\end{array}$}} & \multirow{3}{*}{$\begin{array}{c}\text { 3-th level } \\
R=0.7 \sim 0.9 \\
\begin{array}{c}\text { Major } \\
\text { damage (6) }\end{array}\end{array}$} & \multirow{3}{*}{$\begin{array}{l}\text { 4-th level } \\
R=0.9 \sim 1.0 \\
\begin{array}{c}\text { Near or } \\
\text { collapse (7) }\end{array}\end{array}$} \\
\hline & & & & & & & \\
\hline & & $\begin{array}{c}\text { Minor } \\
\text { Damage (2) }\end{array}$ & $\begin{array}{c}\text { Medium } \\
\text { damage (3) }\end{array}$ & $\begin{array}{c}\text { Medium } \\
\text { damage (4) }\end{array}$ & $\begin{array}{c}\text { Medium } \\
\text { damage (5) }\end{array}$ & & \\
\hline$R_{o}$ & 0.1 & 0.3 & 0.4 & 0.5 & 0.6 & 0.8 & 0.95 \\
\hline$\theta_{\max }$ & $<1 / 550$ & $1 / 550 \sim 1 / 400$ & $1 / 400 \sim 1 / 300$ & $1 / 300 \sim 1 / 200$ & $1 / 200 \sim 1 / 100$ & $1 / 100 \sim 1 / 50$ & $>1 / 50$ \\
\hline
\end{tabular}

In the table 1, the 1,2,3 and 4-th seismic performance levels represent structures subjected to small earthquake, medium earthquake, strong earthquake and Super strong earthquake are not bad, repairable, not collapse and near or collapse, respectively. The first three levels are derived from the code, and the 4-th level is aimed at the situation of near collapse or collapse of structures.

(4) Substitute the failure probability value $P_{f, i}$ of the structure at the $i$-th damage level into Eq. (4), and calculate the probability value $P_{i}$ of the structure at the $i$ th damage level.

$$
P_{i}=P_{f, i-1}-P_{f, i} \quad i=1, \cdots, 7
$$

where $P_{f, 0}=1$.

(5) Defining $R$ is a damage parameter for different seismic performance levels, and $R_{o}$ is the calculated value of $R$ for different damage levels, which are listed in Table 1.

Substitute the damage probability $P$ and the $R_{o}$ corresponding to each damage level into Eq. (4), and calculate the damage index $R_{e}$ which is the mathematical expectation of $R_{o}$.

$$
R_{e}=\sum_{i=1}^{7}\left(R_{o, i} \cdot P_{i}\right)
$$

in which the subscript $i$ represents the corresponding $i$-th damage level in Table 1.

(6) Compare $R_{e}$ with the $R$ range in Table 1 to determine the damage of the structure under different PGA ground motion excitations, and then evaluate whether the structure meets the requirements under different seismic performance levels.

\section{Example model and earthquake records}

\subsection{Designed structural models}

Three six-story structural models were designed for hard soil sites $\left(\mathrm{I}_{0}, \mathrm{I}_{1}\right)$, intermediate soil sites (II,III), and a soft soil site (IV), and designated as structures 1,2 and, 3, respectively. The three structural models have a story height of $3.6 \mathrm{~m}$ and uniform lateral shear stiffness along the story. The interstory damping uses the Rayleigh damping with a damping ratio of $5 \%$. The basic period is $0.61 \mathrm{~s}$ and the fortification intensity is 7 . Table 2 lists the story weight, mode of vibration, and interstory shear strength of the three structural models.

The structural models of this calculation example can be simplified to a multi-degree-of-freedom (MDOF) system. The ideal story hysteretic relationship of these three MDOF systems is a bilinear stiffness model, the yield stiffness coefficient is 0.024 , and the stiffness degradation coefficient is 0.4 .

\subsection{Selected earthquake records}

For the example analysis, 15 horizontal earthquake motion records for hard soil sites $\left(\mathrm{I}_{0}, \mathrm{I}_{1}\right)$, intermediate soil sites (II,III), and a soft soil site (IV), corresponding to B, $\mathrm{C}$ and D respectively for USGS, are selected and listed in Tables. 3. 
Table 2. The main parameters of example models.

\begin{tabular}{rccccc}
\hline \multirow{2}{*}{ Story } & \multirow{2}{*}{$\begin{array}{c}\text { Story gravity load } \\
\text { /kN }\end{array}$} & $\begin{array}{c}\text { The 1-th } \\
\text { mode }\end{array}$ & \multicolumn{3}{c}{ Story shear strength / kN } \\
\cline { 4 - 5 } 1-th & 10360 & 0.25 & 4682 & 6797 & 8916 \\
2-th & 9330 & 0.48 & 4430 & 6383 & 8372 \\
3-th & 9330 & 0.69 & 4000 & 5673 & 7442 \\
4-th & 9330 & 0.85 & 3365 & 4628 & 6071 \\
5-th & 9330 & 0.95 & 2526 & 3247 & 4259 \\
6-th & 6950 & 1.00 & 1484 & 1530 & 2006 \\
\hline
\end{tabular}

Table 3. The information of earthquake records.

\begin{tabular}{|c|c|c|c|c|}
\hline Soil sites & Station & Earthquake & Components & Number \\
\hline \multirow{5}{*}{$\begin{array}{l}\text { Hard } \\
\text { soil } \\
\text { site } \\
\left(\mathrm{I}_{0}, \mathrm{I}_{1}\right)\end{array}$} & 1095 Taft Lincoln School & Kern County (52/7/21,Ms7.7) & TAF021 & Y1 \\
\hline & 1095 Taft Lincoln School & Kern County (52/7/21,Ms7.7) & TAF111 & $\mathrm{Y} 2$ \\
\hline & 14403 LA 116th St School & Northridge $(94 / 1 / 17, M s 6.7)$ & 116090 & Y3 \\
\hline & 6604 Cerro Prieto & Imperial Valley (79/10/15,Ms6.9) & H-CPE147 & Y4 \\
\hline & Tcu045 & ChiChi (99/9/20,Ms7.6) & TCU045-N & Y5 \\
\hline \multirow{5}{*}{$\begin{array}{l}\text { Intermediate } \\
\text { soil } \\
\text { site } \\
\text { (II,III) }\end{array}$} & 90063 GlendaleLas Palmas & Northridge (94/1/17,Ms6.7) & GLP177 & $\mathrm{Z1}$ \\
\hline & 90091 LA Saturn St & Northridge $(94 / 1 / 17, M s 6.7)$ & STN020 & $\mathrm{Z} 2$ \\
\hline & 6621 Chihuahua & Imperial Valley (79/10/15,Ms6.9) & $\mathrm{CHI012}$ & $\mathrm{Z3}$ \\
\hline & 22074 Yermo Fire Station & Landers $(92 / 6 / 28, M s 7.4)$ & YER270 & $\mathrm{Z4}$ \\
\hline & 1028 Hollister City Hall & Loma Prieta $(89 / 10 / 18$, Ms7.1) & HCH090 & $\mathrm{Z} 5$ \\
\hline \multirow{5}{*}{$\begin{array}{l}\text { Soft } \\
\text { soil } \\
\text { site } \\
\text { (IV) }\end{array}$} & 5057 El Centro Array \#3 & Imperial Valley (79/10/15,Ms6.9) & H-E03140 & $\mathrm{R} 1$ \\
\hline & 90011Montebeel- Bluff Rd. & Northridge $(94 / 1 / 17, M s 6.7)$ & BLF206 & $\mathrm{R} 2$ \\
\hline & 0 Shin-Osaka & Kobe (95/01/16,Ms6.9) & SHI000 & $\mathrm{R} 3$ \\
\hline & Ambarli & Kocaeli (99/08/17,Ms7.8) & ATS000 & $\mathrm{R} 4$ \\
\hline & 1002 APEEL 2 - Redwood & Loma Prieta $(89 / 10 / 18$, Ms7.1) & A02043 & R5 \\
\hline
\end{tabular}

\section{Damage probability calculation and seismic performance evaluation}

The PGA of the selected earthquake acceleration is adjusted from 'small to large'. A dynamic time-history analysis with continuously increasing excitation of the structural models is conducted, that is increment dynamic analysis, and $\theta_{\mathrm{m}}$-PGA format capability curves are illustrated in Figure 1.

The damage probability $P$ is calculated by Eq. (3) and Eq. (4), and then the damage index $R_{e}$ is obtained. The damage indexes $R_{e}$ corresponding to different PGA are listed in Table 4 . Through table 4 and $R$ ranges in Table 1, it is intuitive to determine whether the structure model meets the seismic performance requirements under different earthquake intensities.
The Code for Seismic Design of Buildings provides ground motion PGA values under small, medium, and strong earthquakes. The structural models of this calculation example are all fortified at 7 , so the PGA takes values of $0.036,0.100$, and $0.224 \mathrm{~g}$. The $R_{e}$ values corresponding to the three PGA values are listed in Table 5 to evaluate whether the studied structural models meet seismic performance requirements at 1,2 and 3-th levels. From Table 5, it is shown that: according to the method proposed in this paper, the structural model in accordance with the seismic performance level. In particular, under the action of a large earthquake, the structural damage is small, which does not exceed the damage level corresponding to that of a medium earthquake. 


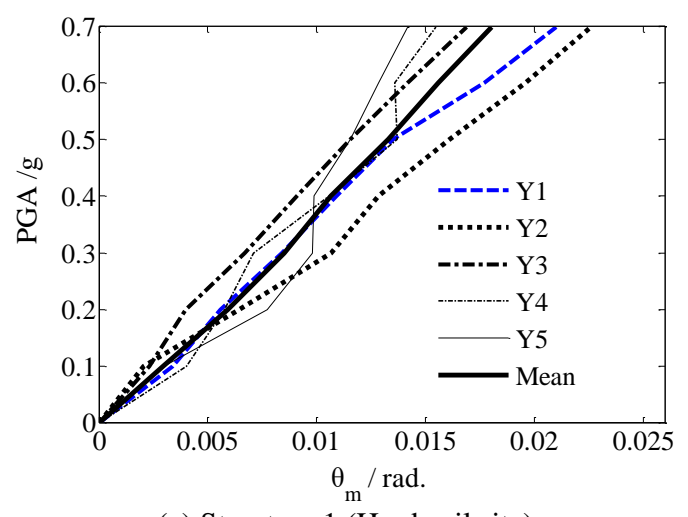

(a) Structure 1 (Hard soil site)

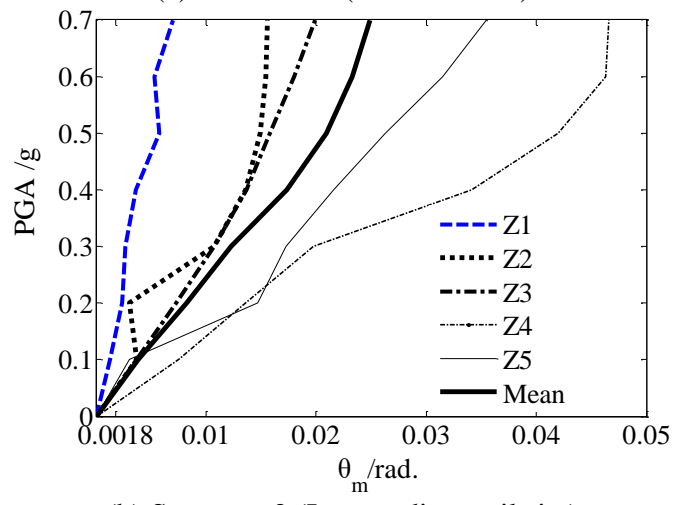

(b) Structure 2 (Intermediate soil site)

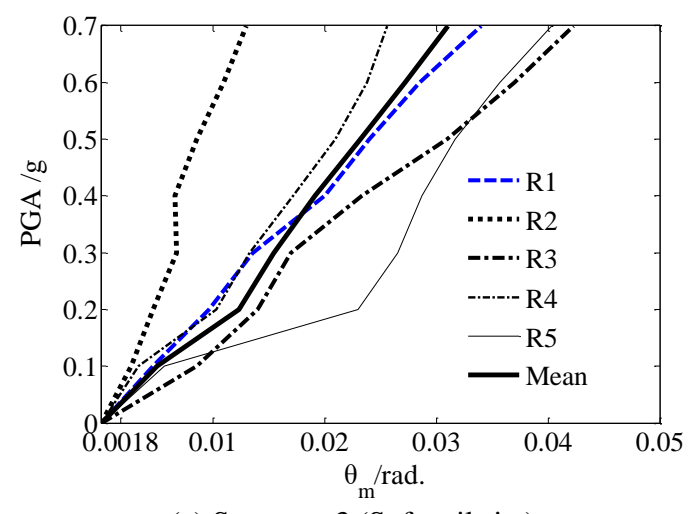

(c) Structure 3 (Soft soil site)

Figure 1. IDA capability curves with $\theta_{\mathrm{m}}$-PGA format.

Table 4. Damage indexes $R_{e}$ of structural models for different PGA.

\begin{tabular}{lcccccccccc}
\hline PGA & $0.1 \mathrm{~g}$ & $0.2 \mathrm{~g}$ & $0.3 \mathrm{~g}$ & $0.4 \mathrm{~g}$ & $0.5 \mathrm{~g}$ & $0.6 \mathrm{~g}$ & $0.7 \mathrm{~g}$ & $0.8 \mathrm{~g}$ & $0.9 \mathrm{~g}$ & $1.0 \mathrm{~g}$ \\
\hline Strucutre1 & 0.228 & 0.444 & 0.575 & 0.665 & 0.733 & 0.789 & 0.832 & 0.868 & 0.896 & 0.917 \\
Strucutre2 & 0.3727 & 0.5912 & 0.7160 & 0.7883 & 0.8376 & 0.8792 & 0.9058 & 0.9270 & 0.9431 & 0.9529 \\
Structure3 & 0.3878 & 0.6021 & 0.7241 & 0.7944 & 0.8481 & 0.8892 & 0.9183 & 0.9341 & 0.9468 & 0.9558 \\
\hline
\end{tabular}

Table 5. The multi-levels seismic evaluation for structural models.

\begin{tabular}{|c|c|c|c|c|}
\hline \multicolumn{2}{|c|}{ Seismic performance levels } & 1-th level & & \\
\hline Small earthquake & $\mathrm{PGA}=0.036 \mathrm{~g}$ & $\star \Delta \triangle$ & & \\
\hline Medium earthquake & PGA $=0.100 \mathrm{~g}$ & & $\star \Delta \triangle$ & \\
\hline Strong earthquake & $\mathrm{PGA}=0.224 \mathrm{~g}$ & & $\star \Delta \triangle$ & \\
\hline
\end{tabular}

Notes: The symbols $\star, \Delta, \triangle$ represent the structure 1,2 and 3, respectively.

\section{Conclusions}

In this paper, a method for evaluating seismic performance of structures is proposed based on seismic fragility analysis, as follows.

(1) The IDA is used to get the relationships between seismic intensities and structural response demands, on this basis, the failure probability equation is given, and then the probabilities with different damage levels under different seismic intensities are obtained.
(2) Damage parameter $R$ is defined and used to reflect seismic damage level of structures, damage index $R_{e}$ is defined and used to compare with $R$ range and determine the situation of seismic damage.

(3) The procedure is given, in which the damage index is calculated to evaluate whether the structure meets the seismic performance requirements at different levels.

In order to validate and demonstrate the proposed method, three structural models are designed according 
to the hard, Intermediate and soft soil sites, respectively, and 15 typical earthquake records are selected as the horizontal earthquake motion excitation of the structural models. The example results show that this method is clear in concept and simple in operation, and it can be used as a seismic design or checking method of structures.

\section{Acknowledgments}

This work was financially supported by the National Natural Science Foundation of China (Grant No. 51478091), the Program for the Natural Science Foundation of Liaoning (Grand No.201602198).

\section{References}

1. C.A. Cornell, F. Jalayer, R.O. Hamburger, J. Struct. Eng. -ASCE, 128, (2002) 526-533.

2. B.R. Ellingwood, O.C. Celik, K. Kinali, Earthq. Eng. Struct. D., 36, (2007) 1935-1952.

3. A.K. Agrawal, M. Ghosn, S. Alampalli, J. Bridge Eng.-ASCE, 17, (2012) 562-575.

4. D.G. Lv, X.H. Yu, J. Building Struct., 10, (2013) 41-48. (in Chinese)

5. D.G. Lv, G.Q. Jin, X.H. Yu, J. Building Struct., 37, (2016) 26-32. (in Chinese)

6. X.H. Yu, D.G. Lv, F. Fan, Eng. Mech., 34, (2017) 69-75. (in Chinese)

7. X.L Lv, N.F. Su, Y. Zhou, J. Earthq. Eng. Eng. Vib., 32, (2012) 19-25. (in Chinese) 